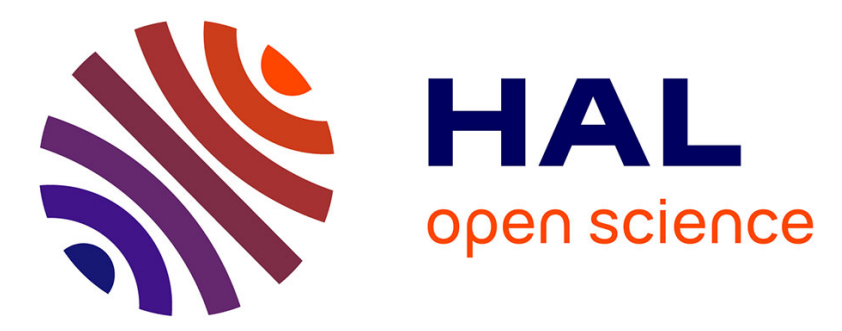

\title{
A Stirling Engine for Automotive Applications
}

Steve Djetel, Sylvie Bégot, François Lanzetta, Eric Gavignet, Wissam S. Bou

Nader

\section{To cite this version:}

Steve Djetel, Sylvie Bégot, François Lanzetta, Eric Gavignet, Wissam S. Bou Nader. A Stirling Engine for Automotive Applications. Vehicle Power and Propulsion Conference, Dec 2017, Belfort, France. hal-02131002

\section{HAL Id: hal-02131002 https://hal.science/hal-02131002}

Submitted on 16 May 2019

HAL is a multi-disciplinary open access archive for the deposit and dissemination of scientific research documents, whether they are published or not. The documents may come from teaching and research institutions in France or abroad, or from public or private research centers.
L'archive ouverte pluridisciplinaire HAL, est destinée au dépôt et à la diffusion de documents scientifiques de niveau recherche, publiés ou non, émanant des établissements d'enseignement et de recherche français ou étrangers, des laboratoires publics ou privés. 


\section{A Stirling engine for automotive applications}

\author{
Steve Djetel, Sylvie Bégot, François Lanzetta, \\ Eric Gavignet \\ FEMTO-ST Institute \\ Univ. Bourgogne Franche-Comté, CNRS \\ Département ENERGIE \\ 90000 Belfort, France \\ steve.djetel@femto-st.fr
}

\author{
Wissam S. Bou Nader \\ Technical center of Vélizy \\ PSA Group \\ 78943 Velizy, France \\ wissam.bounader@mpsa.com
}

\begin{abstract}
This paper describes a Stirling Engine used as an Auxiliary Power Unit in a Series Hybrid Vehicle. The engine modeling is presented, then its integration in the vehicle power train is described. Fuel consumption, power train efficiency are compared between Stirling Engines and Spark ignition Engines. The results show that Stirling engines present good performances compared to internal combustion engines in the same configuration. Finally, the prototype design and first results are presented.
\end{abstract}

Keywords - Stirling engine, Auxiliary Power Unit, Series Hybrid Eletric Vehicle

\section{INTRODUCTION}

The spark-ignition and the diesel engine, both Internal Combustion Engines (ICE), are the only engines in widespread use in the world's automotive transportation systems. Internal combustion engines waste a large portion of the available fuel energy as heat loss via exhaust gas and most of car engines operate with an efficiency rate of about $30 \%$ [1]. Nowadays, the need of alternative propulsion systems with substantially improved fuel economy and adaptability to various fuels contributes to the development of technologies like the Stirling engine. In the 70's, the Department of Energy (DOE) and NASA started a research program, based on the Philips historical technology [2], with the initial objective of developing Stirling alternative automotive heat engines with significantly reduced exhaust emissions [3]. The initial objectives were the development of: (1) new metal alloys, (2) the technology for seals with leakage, friction, and life characteristics suitable for the application, (3) the technology necessary for low-emission combustion systems, (4) component technologies required to reduce engine cost and weight and to improve engine performance and life, (5) identification and evaluation of advanced concepts. The Stirling engine uses a continuous-flow combustor from which heat is transferred to a gaseous working fluid (hydrogen or helium or nitrogen) in a sealed mechanical system. The gaseous working fluid is compressed, heated, expanded against a piston connected to an output shaft and cooled, all in a closed cyclic process (Fig.1). The combustion system is external to the working fluid, in contrast to the combustion process in a spark-ignition engine, diesel or gas turbine, where the fuel and air are combusted under pressure and expanded directly to produce work [4-5]. The Stirling technology is interesting for two major raisons: (1) the theoretical thermodynamic efficiency is limited only to the Carnot efficiency, the maximum obtainable by any heat engine operating between the same maximum and minimum working fluid temperatures and (2) the continuous-flow combustion process is much more controlled than in intermittent internal combustion systems, so that emissions can be limited without degrading engine performance. The continuous combustion also eliminates one of the major sources of noise and vibration found in the ICE [6].

\section{STIRLING ENGINE}

The Stirling engine is a heat engine developed by Robert Stirling in 1816. It uses an external source of energy to heat the gas located inside a cylinder. Therefore it can use several types of heat sources and various types of fuels. Its cycle theoretically has Carnot efficiency. Therefore, this engine is a good candidate for alternative powertrain.

A Stirling engine operates with a closed cycle. In its theoretical cycle (Fig. 1), the working fluid is compressed at the lowest constant temperature $T_{L}(1-2)$ and $Q_{L}$ is the heat rejected. The fluid is heated at constant volume (2-3) by the heat $Q_{R}$ stored in the regenerator. The expansion work at constant temperature (3-4) is generated by the external supplied heat $Q_{H}$ to the gas at the highest temperature $T_{H}$. Finally, the fluid is cooled from $T_{H}$ to $T_{L}$ and the corresponding heat is stored in the regenerator during the process at constant volume (4-1). Both isochoric processes take place into a porous heat exchanger called the regenerator [4-5] whose efficiency is a key point of Stirling engine performances. In motor operation, heat is provided to the engine during the expansion stage (3-4) and rejected to the cold sink in the compression stage (1-2). in vehicles. The engines use two pistons: a piston dedicated to shaft work, and a displacer piston dedicated to the transfer of the gas between the compression and expansion spaces. Several mechanical arrangements are possible for the pistons and cylinders. In this work, a Beta engine where both pistons are in the same cylinder is considered (Fig. 2). With a crankshaft mechanical link, in motor operation the power pistons lags the displacer with an angle of $90^{\circ}$. 


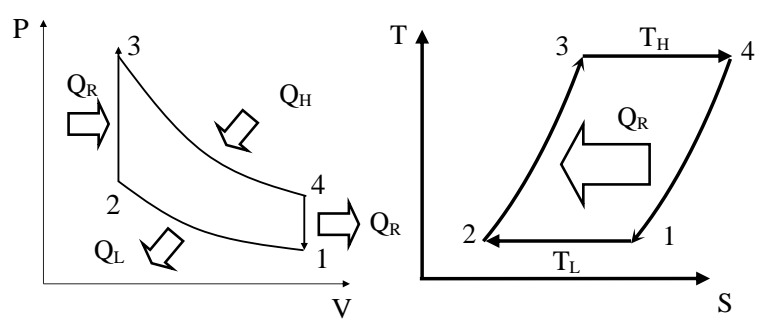

Fig. 1. Theoretical Stirling cycle (PV and TS diagrams)

\section{A. Thermodynamic engine model}

The model is based on the isothermal Schmidt analysis [78]. The following assumptions are made: the transformations in the compression and expansion spaces are isothermal, the mean pressure in the machine can be linearized, the pressure drops in exchangers are linearized, conduction or radiation losses in the machine are neglected. Using these assumptions, the machine is described by the following sets of equations:

$$
p=\frac{m_{g} r}{\frac{V_{c}}{T_{k}}+\frac{V_{k}}{T_{k}}+\frac{V_{r e g}}{T_{r e g}}+\frac{V_{h}}{T_{h}}+\frac{V_{e}}{T_{h}}}
$$

where $p$ denotes the machine mean pressure, $m_{g}$ the mass of gas in the machine, $r$ the gas constant, $V_{c}, V_{k}, V_{r e g}, V_{h}, V_{e}$, the compression, cold exchanger, regenerator, hot exchanger, expansion volumes respectively, $T_{k}, T_{\text {reg, }} T_{h}$, the compression/cold exchanger, regenerator, expansion space/hot exchanger temperature respectively.

$$
\begin{gathered}
V_{e}=V_{c l e}+\frac{V_{s w e}}{2}(1+\cos (\theta+\alpha)) \\
V_{c}=V_{c l c}+\frac{V_{s w c}}{2}(1+\cos (\theta))+\frac{V_{s w e}}{2}(1-\cos (\theta+\alpha))
\end{gathered}
$$

where $V_{c l c}, V_{c l e}$ denotes the compression and expansion clearance volumes respectively, $V_{s w e}, V_{s w c}$ denotes the compression and expansion swept volumes respectively, $\theta$ is the angular position and $\alpha$ is the phase angle between the displacer and piston. The heat exchanged and work during a cycle are computed with:

$$
\begin{gathered}
Q_{i}=W_{i}=\oint p \frac{d V_{i}}{d \theta} d \theta \text { with } i=e, c \\
W=W_{i}+W_{e} \\
\eta=\frac{W}{Q_{e}}
\end{gathered}
$$

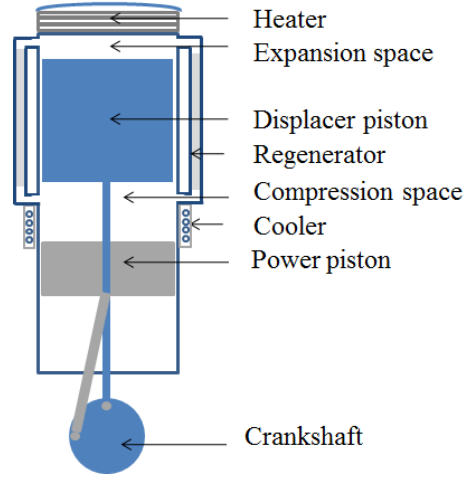

Fig. 2. Schematic of a Beta Stirling engine

where $Q_{i}$ denotes the heat exchanged in the expansion or compression space, $W$ work, and $\eta$ the thermodynamic efficiency. Additional losses are taken into account by modifying $W$ or $Q e$ by the corresponding amount.

The prototype under study characteristics used in the model are presented in TABLE I. The pressure-volume diagram at the engine rated nominal pressure is presented in Fig. 3. Considering an estimated regenerator efficiency of 0.5 , the prototype model is a $15 \mathrm{~kW}$ engine with an efficiency of $42 \%$.

\section{TABLE I. STIRLING ENGINE MODEL CHARACTERISTICS.}

\begin{tabular}{|l|l|l|l|}
\hline \multicolumn{1}{|c|}{ Engine characteristics } & \multicolumn{1}{c|}{ Symbol } & \multicolumn{1}{c|}{ Unit } & \multicolumn{1}{c|}{ Value } \\
\hline Hot temperature & $T_{h}$ & $\mathrm{~K}$ & 937 \\
\hline Cold temperature & $T_{h}$ & $\mathrm{~K}$ & 337 \\
\hline Pressure & $p$ & $\mathrm{~Pa}$ & $60 \times 10^{6}$ \\
\hline Gas constant & $r_{g}$ & $\mathrm{~J} / \mathrm{kg} . \mathrm{K}$ & $296.8\left(\mathrm{~N}_{2}\right)$ \\
\hline Compression swept volume & $V s w c$ & $\mathrm{~m}^{3}$ & $4.5 \times 10^{-4}$ \\
\hline Frequency & $f$ & $\mathrm{~Hz}$ & 35 \\
\hline
\end{tabular}

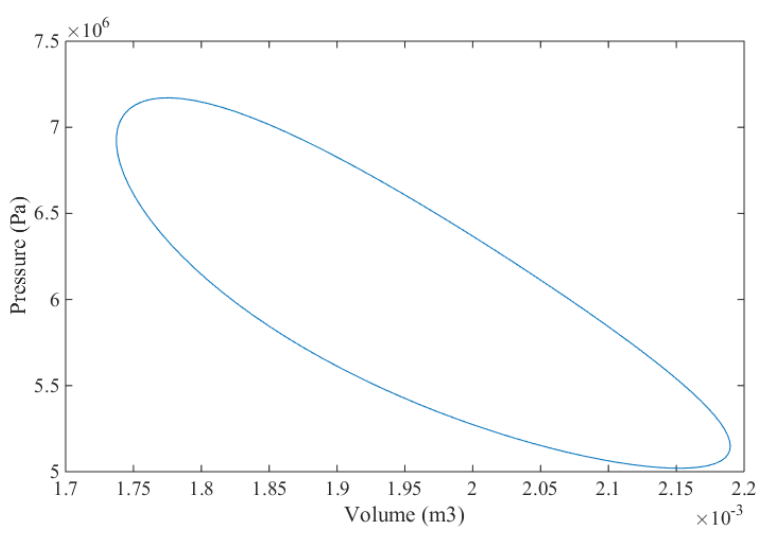

Fig. 3. PV diagram of the engine under study 


\section{3. VEHICLE MODEL}

\section{A. Powertrains setup, components sizing and energy management strategy}

In order to evaluate the benefits of the Stirling machine in terms of fuel savings compared to ICE, a medium-class series hybrid electric vehicle (SHEV), consisting of a Stirling-APU and an electric powertrain is modelled and presented in this section. SHEV combines a thermal and an electric powertrain in a series energy-flow arrangement, as illustrated in Fig. 4. The thermal powertrain consists of a Stirling or ICE energy converter and an electric generator, and is referred to as Auxiliary Power Unit (APU).

The APU is used to recharge the battery once depleted, and the electric powertrain provides the necessary power to overcome the driving load. Consequently, the APU operating speed is cinematically decoupled from the vehicle velocity, and the energy converter operating point is easily controllable to meet its best efficiency. This configuration presents the advantage of tackling one of the main problematics of Stirlingsystems in automotive applications, the machine controllability complexity under transient load [9]. On one side, the Stirling operates in an SHEV at steady power corresponding to the optimum efficiency, which is higher than the maximum efficiency of ICE. On the other side, the vehicle is propelled by an electric motor, powered by a battery and/or the APU, and properly sized to ensure the vehicle acceleration and velocity performance without deficiency.

The powertrain modelling, sizing and equations are presented in [10]. The electric traction motor is sized in order to ensure similar performance to a medium class hybrid vehicle, with maximum speed of $160 \mathrm{~km} / \mathrm{h}$ and acceleration from $0-100 \mathrm{~km} / \mathrm{h}$ in $9.6 \mathrm{~s}$. Consequently, an $80 \mathrm{~kW}$ tractive power electric machine is selected.

The APU is used to ensure the battery sustainability under all driving conditions. Hence, the Stirling and the electric generator are sized taking into consideration urban stop-and-go patterns and highway-driving patterns. The urban stop-and-go patterns are represented in this study by the WLTP. The highway-driving pattern is emulated as driving for a long distance at the maximum velocity of $160 \mathrm{~km} / \mathrm{h}$. Consequently, $40 \mathrm{~kW}$ are required to propel the vehicle at maximum speed on highway compared to $10.4 \mathrm{~kW}$ for the WLTP urban-patterns. Since the highway driving can be achieved by the $80 \mathrm{~kW}$ electric motor, a $12 \mathrm{~kW}$ mechanical Stirling machine is then considered, to ensure the sustainable driving on WLTP without battery needs, while considering the powertrain losses.

Concerning the battery sizing, power and capacity have to be considered. Under any driving conditions, the battery must provide sufficient traction power, with the support of the APU under extreme power demand. Consequently, battery maximum power is sized with respect to the electric motor maximum power and the APU power. A $78 \mathrm{~kW}$ battery is then selected.

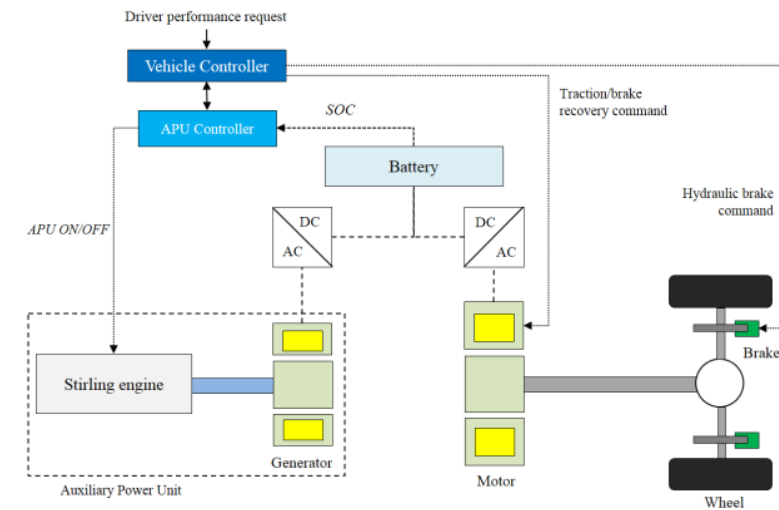

Fig. 4. Stirling APU on Serial Hybrid Electric Vehicles

TABLE II. VEHICLE AND COMPONENTS SPECIFICATIONS.

\begin{tabular}{|c|c|c|c|}
\hline Vehicle specifications & Symbol & Unit & Value \\
\hline Vehicle mass (includ. driver) & $\mathrm{M}_{\mathrm{v}}$ & $\mathrm{kg}$ & 1210 \\
\hline Frontal area & $\mathrm{S}$ & $\mathrm{m}^{2}$ & 2.17 \\
\hline Drag coefficient & $\mathrm{C}_{\mathrm{x}}$ & - & 0.29 \\
\hline Wheel friction coefficient & $\mathrm{f}_{\mathrm{r}}$ & - & 0.0106 \\
\hline Air density & $\rho$ & $\mathrm{kg} / \mathrm{m} 3$ & 1.205 \\
\hline Wheel radius & $\mathrm{R}_{\mathrm{w}}$ & $\mathrm{m}$ & 0.307 \\
\hline Auxiliaries consumption & $\mathrm{P}_{\text {aux }}$ & $\mathrm{W}$ & 750 \\
\hline Battery maximum power & $\mathrm{P}_{\mathrm{b} \max }$ & $\mathrm{kW}$ & 78 \\
\hline Battery capacity & $\mathrm{C}_{\mathrm{b}}$ & $\mathrm{kWh}$ & $5,10,20$ \\
\hline Battery mass & $\mathrm{M}_{\mathrm{b}}$ & $\mathrm{kg}$ & $188,259,356$ \\
\hline Battery state of charge & SOC & - & {$[0.4,0.6,0.8,1]$} \\
\hline Battery open circuit voltage & $\mathrm{V}_{\mathrm{oc}}$ & $\mathrm{V}$ & {$[224,227,228,251]$} \\
\hline Battery internal resistance & $\mathrm{R}_{\mathrm{i}}$ & Ohm & $\begin{array}{c}{[0.31,0.31,0.335} \\
0.385]\end{array}$ \\
\hline Stirling system & $\mathrm{P}_{\text {STI }}$ & $\mathrm{kW}$ & 12 \\
\hline Stirling efficiency & $\eta_{\text {STI }}$ & $\%$ & 39 \\
\hline ICE power & $\mathrm{P}_{\mathrm{ICE}}$ & $\mathrm{kW}$ & 97 \\
\hline ICE max efficiency & $\eta_{\mathrm{ICE}}$ & $\%$ & 36 \\
\hline Generator maximum power & $\mathrm{P}_{\mathrm{g}}$ & $\mathrm{kW}$ & 12 \\
\hline $\begin{array}{c}\text { Generator maximum } \\
\text { efficiency }\end{array}$ & $\eta_{\mathrm{g}}$ & $\%$ & 95 \\
\hline Motor maximum power & $\mathrm{P}_{\mathrm{m}}$ & $\mathrm{kW}$ & 80 \\
\hline Motor maximum efficiency & $\eta_{\mathrm{m}}$ & $\%$ & 93 \\
\hline Transmission ratio & $\mathrm{i}$ & - & 5.4 \\
\hline Transmission efficiency & $\eta_{t}$ & $\%$ & 97 \\
\hline Vehicle total mass & $\mathrm{M}_{\mathrm{t}}$ & $\mathrm{kg}$ & $M_{v}+M_{b}$ \\
\hline Fuel heating value & $\mathrm{H}_{\mathrm{v}}$ & $\mathrm{MJ} / \mathrm{kg}$ & 42.5 \\
\hline
\end{tabular}

As for the capacity, three different values of 5, 10 and 20 $\mathrm{kWh}$ are considered in the analysis in order to assess the impact of the battery size on improving fuel consumption. The additional battery mass is taken into account and values were retrieved from [10].

Based on the above, TABLE II. summarizes the vehicle parameters needed for modelling the SHEV. Note that longitudinal dynamics of the chassis are considered on flat roads and the mass of the Stirling machine is considered equal to the mass of the ICE accessories since plenty of works were done to reduce the mass and size of Stirling engines [9].

Two distinct controllers are considered in the model as illustrated in Fig. 4: the vehicle controller and the APU controller. The vehicle controller is in charge of meeting the 
driver request in terms of performance by controlling the electric motor power. The APU controller monitors the battery SOC; thus, it controls the APU operations in order to maintain the SOC in the desired range. Therefore, an on/off variable $u(t)$ is considered in order to control the APU start operations. The voltage $\mathrm{u}(\mathrm{t})$ takes the value of 0 for APU-off and 1 for APUon.

The dynamic programming (DP), described in [11-12], is considered in this study in order to provide the global optimal strategy to control the APU operations. It decides on the optimal strategy $\mathrm{U}_{\mathrm{opt}}=\{\mathrm{u}(1), \ldots, \mathrm{u}(\mathrm{N})\}_{\text {opt }}$ for the scheduled route at each instant $\mathrm{t}$ while minimizing the fuel cost function $\mathrm{J}$ presented in equation (7). The generic DP function presented in [13] is considered in this study, with the battery SOC as state variable $\mathrm{x}(\mathrm{t})$ and the APU operations as control variable $\mathrm{u}(\mathrm{t})$.

$$
J=\min \left\{\sum_{t=1}^{N} \dot{m}_{f}(\operatorname{soc}(t), u(t)) \times d t_{s}\right\}
$$

with discrete step

$$
\text { time: }
$$

$$
d t_{s}=1
$$

number of time

instances:

$$
N=\frac{n}{d t_{s}} \text { (with } n \text { the time length of }
$$

initial SOC:

$$
\operatorname{SOC}(1)=\operatorname{SOC}_{i}
$$

final SOC:

$$
\operatorname{SOC}(N)=\operatorname{SOC}_{f}
$$

\section{B. Results and discussion}

Two different SHEV configurations are compared in this section: the suggested Stirling-APU and a reference ICEAPU. The Stirling-APU is designed to operate at its optimal operating point and delivers $12 \mathrm{~kW}$ of mechanical power. The ICE-APU uses a 1.2 liters spark ignition engine with maximum efficiency of $36 \%$. During APU operations, the ICE is allowed to operate at any point of its torque-speed map. For both engines, gasoline is the fuel used, and the simulations are performed on a sequence of one to fiverepeated WLTP driving cycles (23 km each), covering driving distances up to $115 \mathrm{~km}$.

The potential of fuel savings of Stirling-APU compared to the ICE-APU is carried out simulating the behavior of plugin hybrids electric vehicles, with the option of battery charging from the grid. Simulations are performed at an initial SOC of $80 \%$ and a final SOC by the end of the trip at $30 \%$.

Fig. 5 shows the energy converters operation for both Stirling and ICE on plug-In SHEVs powertrains on three repeated WLTP with $10 \mathrm{kWh}$ battery capacity. Stirling with lower power, operates at $56 \%$ of time and deliver a constant mechanical power of $12 \mathrm{~kW}$ compared to $22.5 \%$ of time for the ICE with an average power of $19 \mathrm{~kW}$.

Fig. 6 highlights the potential of increasing the battery capacity on reducing the fuel consumption for both StirlingAPU and ICE-APU.

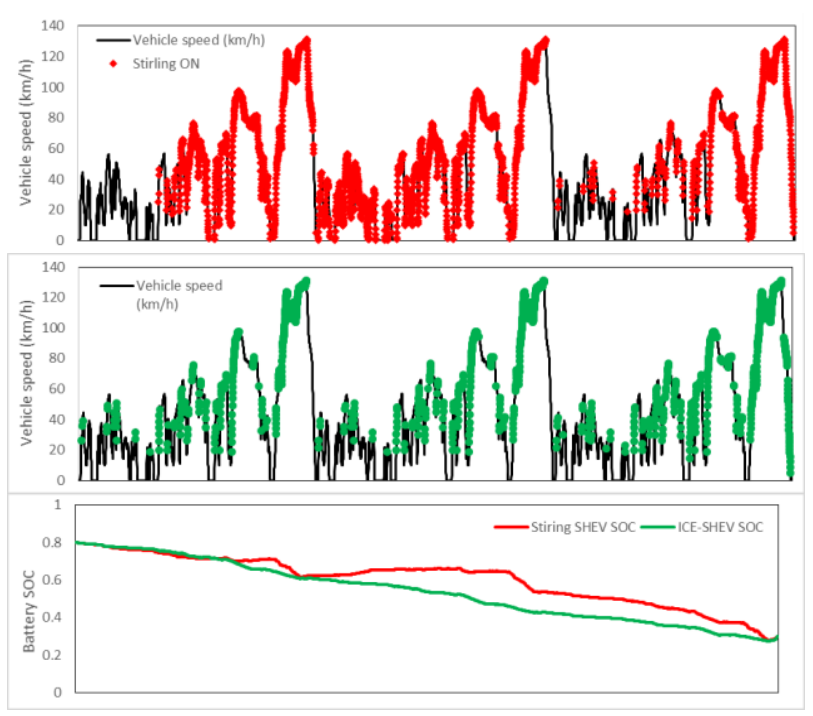

Fig. 5. APU operation and battery SOC results

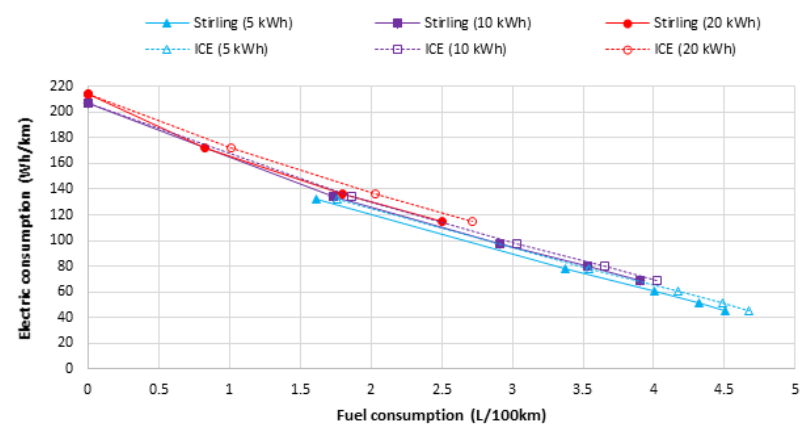

Fig. 6. Battery and fuel energy trade-off for the plug-in configuration on one to five-repeated WLTP, under the three investigated battery capacities

It illustrates the battery electric consumption per driven kilometer as function of the observed fuel consumption on one to five-repeated WLTP driving cycles.

Two conclusions are drawn out of this figure:

- Large battery capacities rely more on electric energy and induce lower fuel consumption. The governing equation of this energy trade-off is expressed in equation (12), with d the driving cycle length, $E_{b_{-} \text {traction }}$ the battery electric energy consumption to overcome the vehicle traction load, $E_{\text {ber }}$ the vehicle load energy recovered through regenerative braking, $E_{f u e l}$ the energy of the consumed fuel and $E_{\text {grid }}$ the consumed electric energy from the grid to recharge the battery from $30 \%$ to $80 \%$ SOC. Therefore, for a given driving cycle length $d$, where $E_{b_{-} \text {traction }}$ and $E_{-b e r}$ remain constant, increasing the battery capacity induces higher charging energy from the grid $E_{\text {grid }}$ and lower fuel consumption $E_{f u e l}$. 


$$
\begin{aligned}
& \frac{E_{b_{\text {traction }}}}{d}=\frac{1}{d}\left(E_{\text {ber }} \times \eta_{m}+E_{\text {fuel }} \times \eta_{\text {APU }}+\right. \\
& \left.\ldots . .+E_{\text {grid }} \times \eta_{\text {charging }}\right)
\end{aligned}
$$

$$
\begin{aligned}
& \frac{E_{b_{\text {traction }}}}{d}=\frac{1}{d}\left(E_{\text {ber }} \times \eta_{m}+E_{\text {fuel }} \times \eta_{\text {APU }}+\ldots+\right. \\
& \left.E_{\text {grid }} \times \eta_{\text {charging }}\right) \\
& E_{b_{\text {traction }}} / d=1 / d\left(E_{\text {ber }} \times \eta_{m}+E_{\text {fuel }} \times \eta_{A P U}+\right. \\
& \left.E_{\text {grid }} \times \eta_{\text {charging }}\right)
\end{aligned}
$$

- Higher fuel consumption is observed in the ICE-APU SHEV model compared to Stirling-APU, for the three battery capacities. In fact, the Stirling-APU performs more efficiently than the ICE-APU, which leads to a higher powertrain efficiency, as illustrated in Fig. 7. The powertrain efficiency is computed using equation (13). It is noteworthy to mention that for short driving cycle length d (1 WLTP) and large battery capacities (10 and $20 \mathrm{kWh}$ ), the APU is not required to turn on, and the whole distance is travelled in electric mode only.

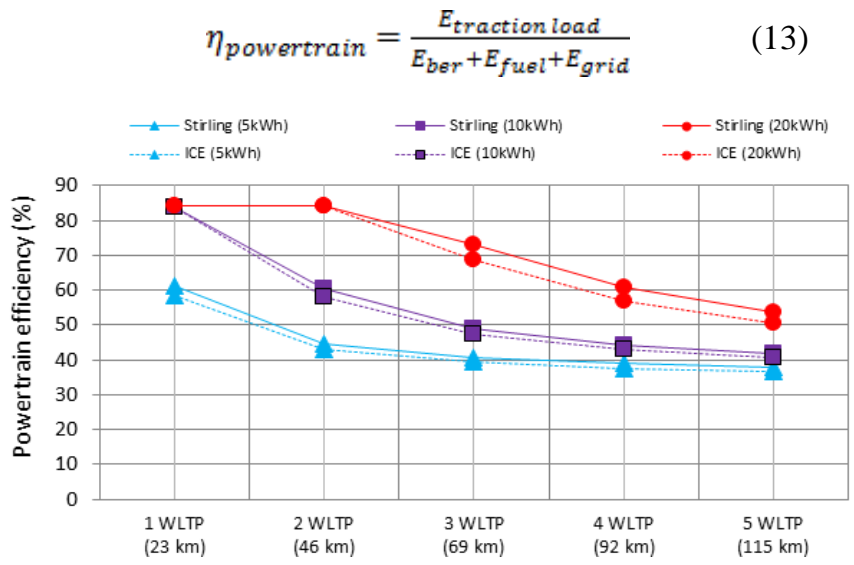

Fig. 7. Powertrain efficiency of the plug-in configuration, on one to fiverepeated WLTP, under the three investigated battery capacities

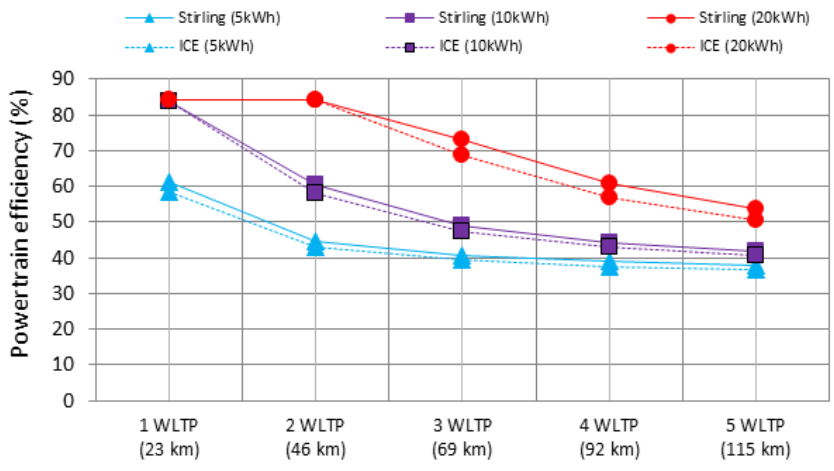

Fig. 8. Fuel consumption results between Stirling-system and ICE of the plug-in on one to five-repeated WLTP, under the three investigated battery capacities
Finally, comparing the fuel consumption results between the Stirling-APU and the ICE-APU (Fig. 8), 3\% to $8 \%$ fuel savings are observed. As detailed above, these savings are explained by the higher operating efficiency of the Stirling, since it was constrained to operate at its optimal efficiency of $39 \%$. Although the ICE was not constrained to operate at one operating point, results showed that ICE operation was at the optimal operating line (OOL) where the efficiency remains between 34 and $36 \%$, almost at its maximum efficiency of $36 \%$.

\section{STIRLING ENGINE PROTOTYPE}

\section{A. Design}

The prototype and the test bench are presented in the Fig. 9. The schematic of the engine is a Beta configuration (Fig. 2). The rated power of the engine is $10 \mathrm{~kW}$, the rated pressure is 60 bars. It operates between a hot source at $950 \mathrm{~K}$ and a cold sink of about $300 \mathrm{~K}$. The gas used is nitrogen. The prototype main characteristics are presented in the TABLE III. In the experimental campaign, the heat source is a gas heater. The engine is water-cooled. The shaft is linked to an electric motor and a power electronics converter. The instrumentation includes different sensors: temperature sensors (expansion and compression spaces, cooling circuit), pressure sensors (expansion and compression spaces), and a torque and rotational speed sensor.

TABLE III. PROTOTYPE STIRLING ENGINE CHARACTERISTICS

\begin{tabular}{|l|l|l|l|}
\hline \multicolumn{1}{|c|}{ Engine characteristics } & \multicolumn{1}{c|}{ Symbol } & \multicolumn{1}{c|}{ Unit } & \multicolumn{1}{c|}{ Typ. Value } \\
\hline Hot temperature & $T_{h}$ & $\mathrm{~K}$ & 950 \\
\hline Cold temperature & $T_{h}$ & $\mathrm{~K}$ & 300 \\
\hline Pressure & $p$ & $\mathrm{~Pa}$ & $60 \times 10^{6}$ \\
\hline Gas constant & $r_{g}$ & $\mathrm{~J} / \mathrm{kg} . \mathrm{K}$ & $296.8\left(\mathrm{~N}_{2}\right)$ \\
\hline Frequency & $f$ & $\mathrm{~Hz}$ & 50 \\
\hline Power piston diameter & $d$ & $\mathrm{~m}$ & $10^{-2}$ \\
\hline Compression swept volume & $V s w c$ & $\mathrm{~m}^{3}$ & $4.5 \times 10^{-4}$ \\
\hline
\end{tabular}

The sensors are connected to a real-time acquisition system.

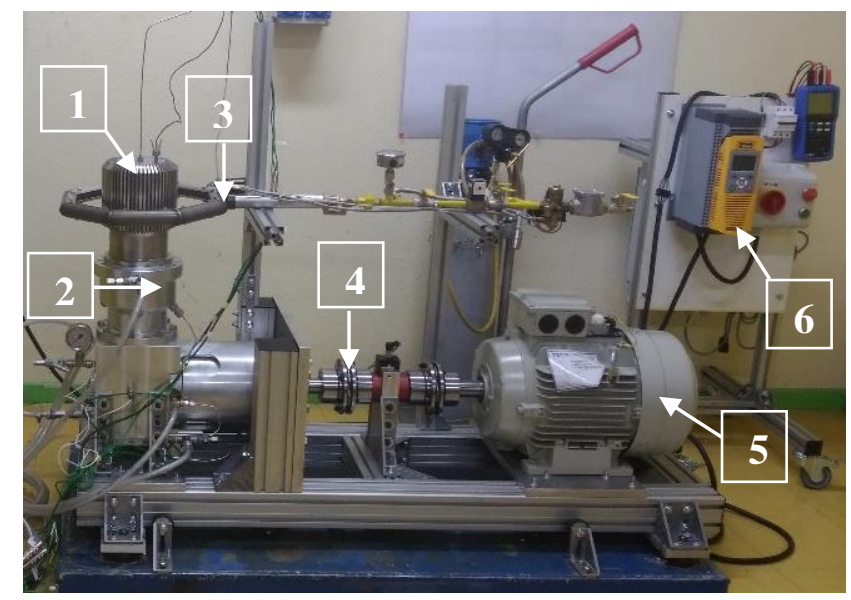

Fig. 9. Stirling engine prototype: 1 expansion space, 2 compression space, 3 gas heater, 4 shaft, 5 electrical engine, 6 power eletronics converter 


\section{B. First results}

In this first experimental phase, the engine is powered through the electric engine and therefore operated as a heat pump. The pressure variation in the expansion and compression spaces are plotted in the Fig. 10. We observe a periodic variation of about $20 \%$ around the engine mean pressure. The compression ratio is rather low, this is characteristic in Stirling engines because they operate on a closed cycle. The discrepancy between the values in the compression and expansion spaces are due to pressure losses in the three heat exchangers. The regenerator usually is the major contributor to these pressures losses.

The torque and rotational speed are presented in the Fig. 11 and Fig. 12. The curves also present a periodic variation with an acyclism characteristic of these engines. We observe that the torque reaches its maximum value $(110 \mathrm{Nm})$ in the compression phase. Consequently, the rotational speed is minimal $(590 \mathrm{rpm})$ at this stage of the cycle. The torque is minimal $(20 \mathrm{Nm})$ in the expansion stage. Between these two points, we observe a raise in the torque when the displacer piston speed changes of sign. The electric power, at mean rotational speed of $600 \mathrm{rpm}$, is $6 \mathrm{~kW}$ leading a corresponding pressure of 18 bar.

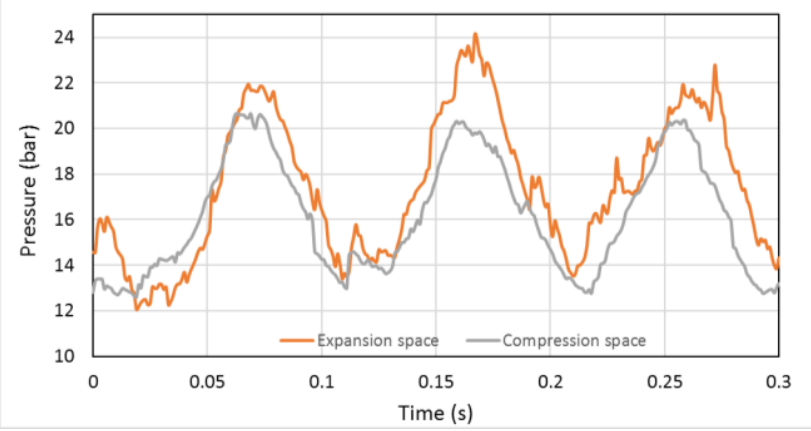

Fig. 10. Pressure variation in the engine

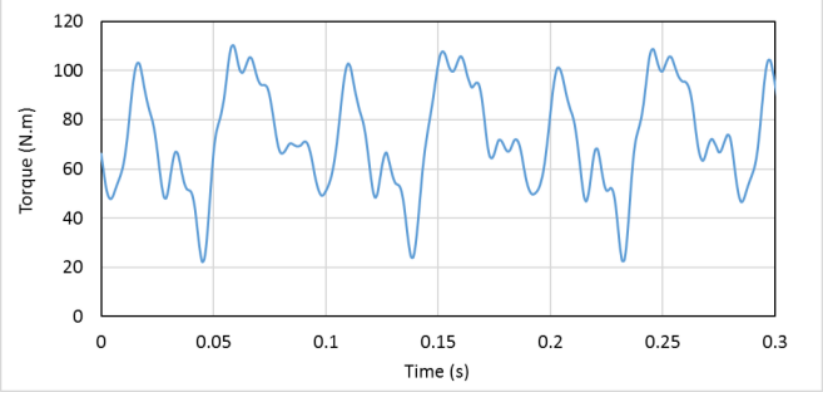

Fig. 11. Torque variation (at mean rotational speed $\mathrm{N}=600 \mathrm{rpm}$ )

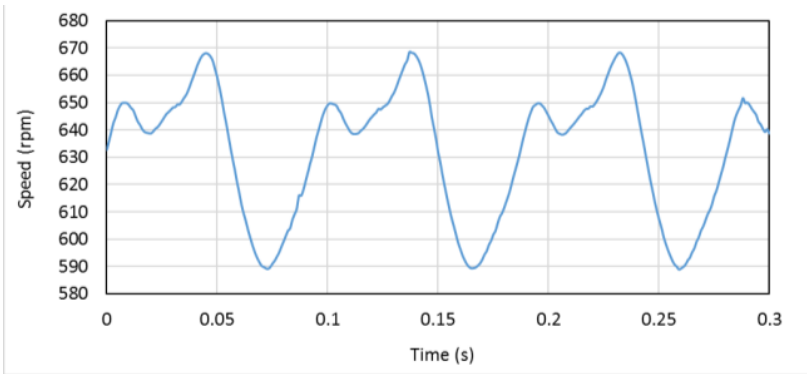

Fig. 12. Instantaneous rotational speed

\section{CONCLUSION}

To address the need of developing alternative automobile powertrains, an APU for Series Hybrid Vehicles including a Stirling engine has been presented. Simulation results showed that powertrain efficiencies and fuel consumption present good performances when compared to a conventional ICE APU. The design and first experimental results of a prototype $10 \mathrm{~kW}$ Stirling engine prototype have been presented.

\section{ACKNOWLEDGMENT}

This work has been supported by the Région Bourgogne Franche-Comté.

\section{REFERENCES}

[1] J.G. Ruiz, "Waste Heat Recovery in Automobile Engines: Potential Solutions and Benefits", Master of Science in Mechanical Engineering, Massachusetts Institute of Technology, 2005.

[2] [2] R.J. Meijer, The Philips thermal engine: Analysis of the rhombic drive mechanism and efficiency measurements, 1960.

[3] [3] D.G. Beremand, R.K. Shaltens, "NASA/DOE Automotive Stirling Engine Project", NASA TM-87345, 1986.

[4] G. Walker, Stirling engines. Oxford: Clarendon Press; 1981.

[5] G.T. Reader, C. Hooper, Stirling Engines. London New-York: E.\&F.N.Spon, 1983.

[6] K. Mollenhauer, K. Tschöke, Handbook of Diesel engine, Springer, 2010.

[7] I. Urieli, D.M. Berchowitz, Stirling Cycle Analysis, Adam Hilger, Bristol, 1984

[8] S. Bégot, G. Layes, F. Lanzetta, P. Nika, "Stability analysis of free piston Stirling engines”, Eur. Phys. J. Appl. Phys. vol. 61, n³, pp. 1-16, 2013.

[9] N. Nightingale, "Automotive Stirling Engine: Mod II Design Report", National Aeronautics and Space Administration, Lewis Research Center, DOE/NASA/0032-28, October 1986.

[10] W. Bou Nader, C. Mansour, M. Nemer and O. Guezet, "Exergotechnological explicit methodology for gas-turbine system optimization for series hybrid electric vehicles", Proceedings of the Institution of Mechanical Engineers, Part D : Journal of Automobile Engineering, 2017

[11] C.J. Mansour, "Trip-based optimization methodology for a rule-based energy management strategy using a global optimization routine: The case of the Prius plug-in hybrid electric vehicle". Proceedings of the Institution of Mechanical Engineers, Part D: Journal of Automobile Engineering, vol. 230, $\mathrm{n}^{\circ} 11$, pp. 1529-1545, 2016.

[12] C.J. Mansour and D. Clodic, "Optimized energy management control for the Toyota Hybrid System using dynamic programming on a predicted route with short computation time", International Journal of Automotive Technology, vol 13, n², pp. 309-324, 2012.

[13] O. Sundstrom and L. Guzzella, "A generic dynamic programming Matlab function”. 2009 IEEE Control Applications, (CCA) \& Intelligent Control, (ISIC). St. Petersburg, 2009, pp. 1625-1630. doi: 10.1109/CCA.2009.5281131 